\title{
Rationally re-designed mutation of NAD-independent L-lactate dehydrogenase: high optical resolution of racemic mandelic acid by the engineered Escherichia coli
}

Tianyi Jiang ${ }^{1}$, Chao Gao ${ }^{1}$, Peipei Dou ${ }^{1,2}$, Cuiqing $\mathrm{Ma}^{1 *}$, Jian Kong ${ }^{1}$ and Ping $\mathrm{Xu}^{2,1^{*}}$

\begin{abstract}
Background: NAD-independent L-lactate dehydrogenase (L-iLDH) from Pseudomonas stutzeri SDM can potentially be used for the kinetic resolution of small aliphatic 2-hydroxycarboxylic acids. However, this enzyme showed rather low activity towards aromatic 2-hydroxycarboxylic acids.

Results: Val-108 of L-iLDH was changed to Ala by rationally site-directed mutagenesis. The L-iLDH mutant exhibited much higher activity than wide-type L-iLDH towards L-mandelate, an aromatic 2-hydroxycarboxylic acid. Using the engineered Escherichia coli expressing the mutant L-iLDH as a biocatalyst, $40 \mathrm{~g} \cdot \mathrm{L}^{-1}$ of DL-mandelic acid was converted to $20.1 \mathrm{~g}^{\mathrm{L}} \mathrm{L}^{-1}$ of D-mandelic acid (enantiomeric purity higher than $99.5 \%$ ) and $19.3 \mathrm{~g} \cdot \mathrm{L}^{-1}$ of benzoylformic acid.

Conclusions: A new biocatalyst with high catalytic efficiency toward an unnatural substrate was constructed by rationally re-design mutagenesis. Two building block intermediates (optically pure D-mandelic acid and benzoylformic acid) were efficiently produced by the one-pot biotransformation system.
\end{abstract}

Keywords: NAD-independent L-lactate dehydrogenase, Site-directed mutagenesis, Optical resolution, D-mandelic acid

\section{Background}

D-Mandelic acid, an aromatic 2-hydroxycarboxylic acid, is a valuable chiral building block for the synthesis of various pharmaceuticals, such as anti-obesity agents, antitumor agents, penicillins, and semisynthetic cephalosporins [1-3]. Chemical processes for mandelic acid production result in the racemic mixture of both stereospecific forms. Several biocatalytic methods, including lipase catalyzed enantioselective esterification [4], oxidoreductase catalyzed enantioselective oxidation, and microbial mediated enantioselective degradation [5-10], have been developed to prepare D-mandelic acid from racemic mandelic acid. Among these routes, oxidative resolution of racemic mandelic acid is much more

\footnotetext{
* Correspondence: macq@sdu.edu.cn; pingxu@sjtu.edu.cn

${ }^{1}$ State Key Laboratory of Microbial Technology, Shandong University, Jinan 250100, China

Full list of author information is available at the end of the article
}

promising because of its easy manipulation, exclusion of co-substrate addition, and high yield.

The NAD-independent L-lactate dehydrogenase (L-iLDH) of Pseudomonas stutzeri SDM is located on the cell membrane, and quinine, as its electron acceptor, could be directly regenerated by the membrane electron transport chain [11]. So it may exhibit higher catalytic efficiency than the soluble FMN-dependent $\alpha$-hydroxyacid dehydrogenases. Previous report showed that it exhibits high catalytic efficiency and enantioselectivity toward small aliphatic 2-hydroxycarboxylic acids such as L-lactate and L-2-hydroxybutanoate [12]. Cells of P. stutzeri SDM have been used in the kinetic resolution of lactate and 2-hydroxybutanoate racemic mixtures to produce D-lactate and D-2-hydroxybutanoate [13,14]. Considering the similar structures of lactic acid and mandelic acid, L-iLDH might also be able to catalyze the kinetic resolution of racemic mandelic acid (Figure 1). 


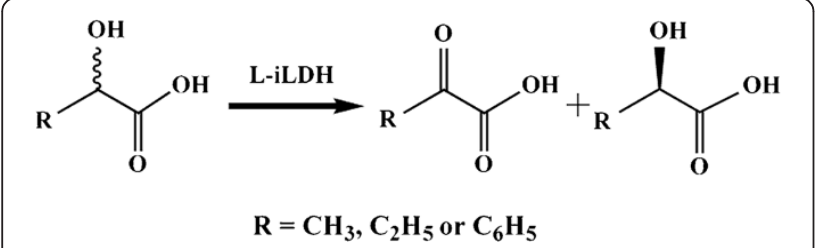

Figure 1 Scheme for kinetic resolution of 2-hydroxycarboxylic acids. $\mathrm{R}$ is $\mathrm{CH}_{3}$ : lactic acid [13]; $\mathrm{C}_{2} \mathrm{H}_{5}$ : 2-hydroxybutyric acid [14]; $\mathrm{C}_{6} \mathrm{H}_{5}$ : mandelic acid.

L-iLDH from $P$. stutzeri SDM was purified, and then it was characterized further [12]. It showed rather low activity towards L-mandelate [12], which restricts its potential application for the kinetic resolution of racemic mandelic acid.

In recent years, rational re-design mutagenesis has emerged as a practical technique for the construction of biocatalysts with high catalytic efficiencies toward unnatural substrates, like the re-design of phenylalanine dehydrogenase [15-19], NAD-dependent L-lactate dehydrogenase [20], and D-amino-acid oxidase [21]. In this study, L-iLDH from $P$. stutzeri SDM was rationally redesigned on the basis of the sequence alignment and active site structure of its homologous enzyme flavocytochrome $b_{2}$ [22]. The mutant enzyme was expressed in E. coli, purified, and characterized. L-Mandelate dehydrogenation activity of the mutant enzyme was successfully enhanced. Whole cells of E. coli expressing the mutant L-iLDH were then used to perform the kinetic resolution of racemic mandelic acid.

\section{Results and discussion}

\section{Rationally re-designed mutation}

$\mathrm{L}$-iLDH is a member of the L- $\alpha$-hydroxyacid-oxidizing flavoprotein family, and is therefore related both structurally and by sequence to a number of other enzymes, including flavocytochrome $b_{2}$ from Saccharomyces cerevisiae [22]. The X-ray crystal structure of flavocytochrome $b_{2}$ has been resolved (PDB ID code 1FCB), and the active site for 2 - $\alpha$-hydroxyacid dehydrogenation has been identified [23]. Six amino acids which interact directly to the substrate have been pinpointed in the crystal structure [24], in which four amino acids are highly conserved in this protein family. However, the other two residues, Ala-198 and Leu-230 in flavocytochrome $b_{2}$, which interact with the alkyl group of substrates, are not well conserved (Additional file 1 Figure S1). They are considered important for the substrate specificity of the enzyme [24]. As an aromatic 2-hydroxycarboxylic acid, L-mandelic acid is similar in structure with L-lactic acid except that phenyl group replaces alkyl group (Figure 1). Double mutation of the Ala-198 and Leu-230 to amino acids with smaller side chains (Gly and Ala, respectively) increased the ability of flavocytochrome $b_{2}$ to utilize Lmandelate as a substrate [25]. The altered substrate specificity may result from enlargement of the active site space to accommodate the phenyl group [25].

Considering the similarity of active site structures of this protein family, there may also be key residues affecting the substrate specificity of L-iLDH. However, the overall sequence identity of L-iLDH with flavocytochrome $b_{2}$ is only $29 \%$, which is relatively low for providing an accurate model of L-iLDH by homology modeling. So sequence alignment was performed to indentify these residues. The result suggests that the corresponding residues of flavocytochrome $b_{2}$ Ala-198 and Leu-230 are Gly-79 and Val-108, respectively, in L-iLDH (Figure 2). Gly-79 is the amino acid having smallest side chain and is the same amino acid as in the mutant flavocytochrome $b_{2}$ with increasing L-mandelic acid dehydrogenase activity [25]. However, as the Leu-230 in flavocytochrome $b_{2}$, the Val-108 of L-iLDH has a larger side chain than Ala, which may narrow the active site space of L-iLDH. Therefore, Val-108 was selected to be mutated to Ala to increase the L-mandelate dehydrogenase activity of L-iLDH.

\section{Kinetics of V108A L-iLDH}

V108A L-iLDH was expressed in E. coli C43 (DE3), and it was purified using the protocol reported for the wildtype L-iLDH [12]. The activity of wild-type L-iLDH for L-mandelate was below the detection limit for a reliable measurement with 3-(4, 5-dimethylthiazol-2-yl)-2, 5-diphenyltetrazolium bromide (MTT) as the electron acceptor [12]. However, when the reaction time was extended, the oxidation product benzoylformate could be detected by HPLC, suggesting weak activity of L-iLDH for L-mandelate. The more sensitive electron acceptor 2,6dichloroindophenol (DCIP) was used to determine the accurate kinetic parameters of the enzyme.

As shown in Table 1, the activity of L-iLDH towards L-mandelate was low, with a $k_{\text {cat }}$ value of only $8.3 \pm 1.3 \mathrm{~s}^{-1}$ (compared with a value of $445 \pm 44 \mathrm{~s}^{-1}$ for L-lactate). The $K_{\mathrm{m}}$ with L-mandelate as a substrate was $6.8 \pm 1.0 \mathrm{mM}$, which was 38 -fold higher than that of L-lactate. The V108A mutant enzyme resulted in a 12-fold increase in the $K_{\text {cat }}$ value with L-mandelate, and the $K_{\mathrm{m}}$ was decreased to $1.6 \pm 0.1 \mathrm{mM}$. Therefore, the catalytic efficiency (based on the $k_{\text {cat }} / K_{\mathrm{m}}$ value) was increased by 50.8-fold for the V108A mutant compared to the wildtype enzyme. The catalytic efficiency of the mutant enzyme with L-lactate had a nearly 10 times lost. However, the value was still 3.8 folds higher than with L-mandelate, which differed from the case of $S$. cerevisiae flavocytochrome $b_{2}$, in which the optimum substrate was altered from L-lactate to L-mandelate by the double mutation [25]. No reverse action activity or 


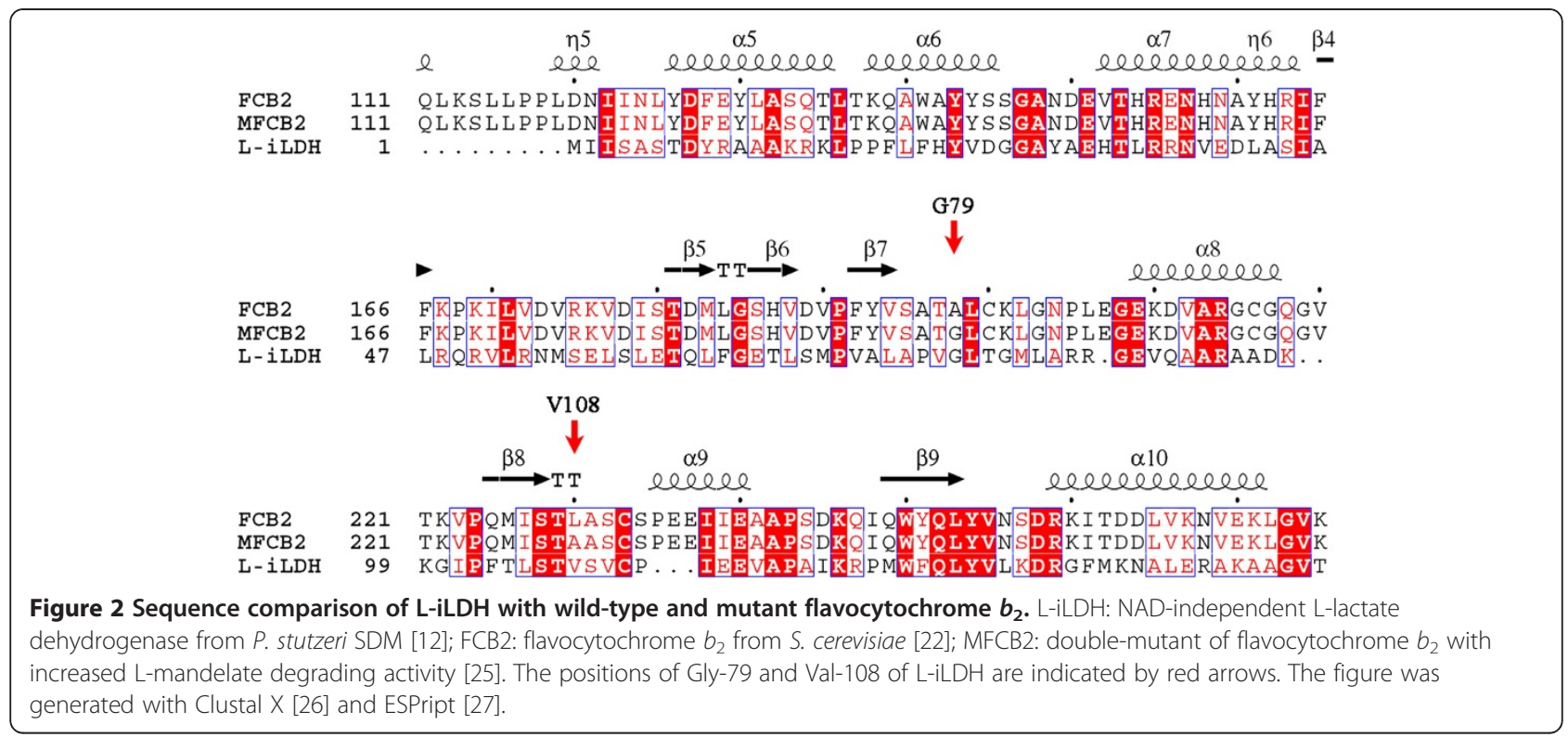

activity with D-mandelate of the mutant L-iLDH was detected. D-Mandelate competitively inhibited V108A L-iLDH activity towards L-mandelate. The $K_{\mathrm{i}}$ value was estimated to be $5.5 \pm 0.5 \mathrm{mM}$ (Additional file 2 Figure S2). Effect of the mutation on stability of the mutated enzyme in comparison with the wild-type enzyme was also investigated. Within the selected range, no remarkable change of the enzyme stability as function of temperature and $\mathrm{pH}$ was observed (Additional file 3 Figure S3).

\section{Feasibility in co-production of D-mandelic acid and benzoylformic acid}

Since the mutant L-iLDH was shown to oxidize L-mandelate to benzoylformate, the feasibility of kinetic resolution of DL-mandelic acid by the enzyme was further studied. E. coli, a non-native microbe for the degradation of mandelic acid, was selected as a suitable host for the kinetic resolution of DL-mandelic acid. To verify that the engineered E. coli strains exhibited mandelic acid oxidation activity, the capacity for L-mandelic acid oxidation of the $2 E$. coli strains expressing wild type or V108A L-iLDH was detected and compared. As shown in Figure 3A, by using $12.5 \mathrm{~g}$ dry cell weight (DCW) $\mathrm{L}^{-1}$ of $E$. coli expressing V108A L-iLDH as the biocatalyst and $10 \mathrm{~g} \cdot \mathrm{L}^{-1}$ of L-mandelic acid as the substrate, L-mandelic acid in the reaction system was degraded completely within $20 \mathrm{~h}$. By contrast, $2.7 \mathrm{~g} \cdot \mathrm{L}^{-1}$ of L-mandelic acid remained after $28 \mathrm{~h}$ of reaction with the same reaction system by using the cells expressing wild-type enzyme. Furthermore, when using racemic mandelic acid as the substrate, about half of total mandelic acid could not be degraded (Figure 3B), which was determined to be the D-enantiomer (Additional file 4 Figure S4). The inhibition effect of D-mandelic acid may have on the rate of reaction was further investigated. Different concentrations of D-mandelic acid (from $0 \mathrm{~g} \cdot \mathrm{L}^{-1}$ to $30 \mathrm{~g} \cdot \mathrm{L}^{-1}$ ) were added to reaction system containing $10 \mathrm{~g} \cdot \mathrm{L}^{-1}$ L-mandelic acid, and biocatalyst activity was evaluated after $4 \mathrm{~h}$ of reaction. The result showed that D-mandelic acid did not affect the catalytic efficiency remarkably (Additional file 5 Figure S5). These results suggest that the whole-cell biocatalyst of $E$. coli expressing V108A L-iLDH has the potential to produce highly pure D-mandelic acid and benzoylformic acid from racemic mandelic acid.

\section{Optimization of biocatalysis conditions}

To increase the efficiency of whole-cell biocatalysis in the kinetic resolution of DL-mandelic acid, the bioconversion conditions were optimized. Benzoylformic acid could be degraded by microbial cells as other 2-keto-acids

Table 1 Kinetics of wild-type (WT) and V108A L-iLDH

\begin{tabular}{|c|c|c|c|c|c|c|}
\hline \multirow[t]{2}{*}{ Substrate } & \multicolumn{3}{|c|}{ WT L-iLDH } & \multicolumn{3}{|c|}{ V108A L-iLDH } \\
\hline & $K_{\text {cat }}\left(\mathrm{s}^{-1}\right)$ & $K_{\mathrm{m}}(\mathrm{mM})$ & $K_{\text {cat }} / K_{\mathrm{m}}\left(\mathrm{mM}^{-1} \mathrm{~s}^{-1}\right)$ & $K_{\text {cat }}\left(\mathrm{s}^{-1}\right)$ & $K_{\mathrm{m}}(\mathrm{mM})$ & $K_{\text {cat }} / K_{\mathrm{m}}\left(\mathrm{mM}^{-1} \mathrm{~s}^{-1}\right)$ \\
\hline L-Lactate & $445 \pm 44$ & $0.18 \pm 0.01$ & 2472 & $185 \pm 36$ & $0.8 \pm 0.1$ & 231 \\
\hline L-Mandelate & $8.3 \pm 1.3$ & $6.8 \pm 1.0$ & 1.2 & $97 \pm 13$ & $1.6 \pm 0.1$ & 61 \\
\hline
\end{tabular}

All experiments were carried out at $30^{\circ} \mathrm{C}$ in $1 \mathrm{~mL}$ of $50 \mathrm{mM}$ Tris- $\mathrm{HCl}(\mathrm{pH} 7.5)$, with DCIP $(0.0625 \mathrm{mM})$ as the electron acceptor. Values for $k_{\text {cat }}$ are expressed as electrons transferred per second per molecule of enzyme. $K_{\mathrm{m}}$ values are expressed in terms of $\mathrm{mM}$ of substrate. 

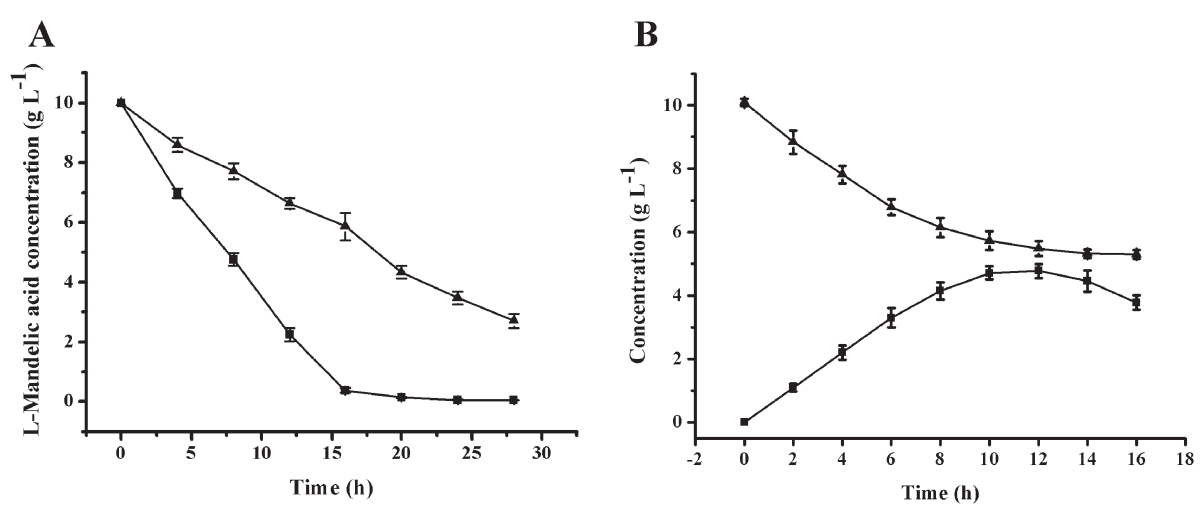

Figure 3 Identifying the feasibility of co-production of D-mandelic acid and benzoylformic acid by E. coli expressing V108A L-iLDH. (A) Comparison of capacities for degrading L-mandelic acid of E. coli strains expressing wild-type or V108A L-iLDH. ( $\mathbf{\Delta}$ ) The catalytic process of the E. coli strain expressing wild-type L-iLDH; (-) The catalytic process of the E. coli strain expressing V108A L-iLDH. (B) The catalytic process of the E. coli strain expressing V108A L-iLDH with racemic mandelic acid as the substrate. ( $\bullet$ ) Concentration of racemic mandelic acid; (-) Concentration of benzoylformic acid. Values are the mean \pm SD of 3 separate determinations.

(Figure 3B and Additional file 6 Figure S6). The degradation decreased the bioconversion ratio and produced some by-products. EDTA was added at a concentration of $20 \mathrm{mM}$ in the reaction system, which removed bivalent ions necessary for 2-keto-acid decarboxylase-catalyzed reactions [28] and then prevents the degradation of benzoylformic acid (Additional file 6 Figure S6).

Since $\mathrm{pH}$ and temperature are parameters that often limit enzyme activity and stability in technical applications, studies addressing the effects of temperature and $\mathrm{pH}$ on whole-cell catalysis were performed. The optimal $\mathrm{pH}$ was found to be 7.0 after adjusting the $\mathrm{pH}$ of the reaction system from 4.0 to 10.0 (Figure 4A). The effect of the reaction temperature was examined in the range of $16^{\circ} \mathrm{C}$ to $58^{\circ} \mathrm{C}$ after $4 \mathrm{~h}$ and $10 \mathrm{~h}$ of reaction. As shown in Figure $4 \mathrm{~B}$, with increasing temperature, higher activity of the biocatalyst was observed over the short term, as shown by the benzoylformic acid production after $4 \mathrm{~h}$ of reaction. However, the activity decreased more rapidly at higher temperatures, as shown by the benzoylformic acid production after $10 \mathrm{~h}$ of reaction. The optimal reaction temperature was chosen to be $42^{\circ} \mathrm{C}$, which optimized enzyme activity and stability. Either the lower activity at lower temperature or the lower stability at higher temperature may cause a decrease of overall L-mandelic acid degrading capacity of the biocatalyst, which will then decrease the production capacity of D-mandelic acid.

The optimal concentration of DL-mandelic acid for the biotransformation was then determined (Table 2). When the biocatalyst was prepared from $25 \mathrm{~g}(\mathrm{DCW}) \mathrm{L}^{-1}$ of $E$. coli, the biotransformation efficiency only decreased slightly as the DL-mandelic acid concentration increased. A higher substrate concentration will result in higher concentrations of products and simplifies the downstream process. The reaction with $40 \mathrm{~g} \cdot \mathrm{L}^{-1}$ of DL-mandelic acid as the substrate exhibited relatively high concentrations of benzoylformic acid and D-mandelic acid with high optical purity.
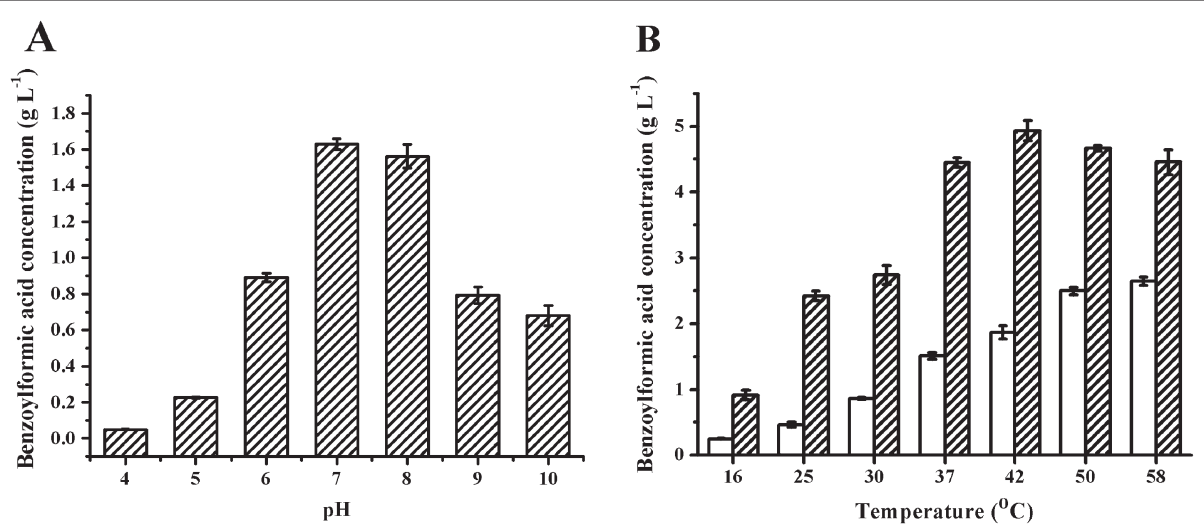

Figure 4 Optimization of $\mathrm{pH}$ and temperature for biocatalysis. (A) Optimization of $\mathrm{pH}$. (B) Optimization of temperature. Unshaded bars represent the production of benzoylformic acid in $4 \mathrm{~h}$. Shaded bars represent the production of benzoylformic acid in $10 \mathrm{~h}$. Values are the mean $\pm \mathrm{SD}$ of 3 separate determinations. 
Table 2 Effect of DL-mandelic acid concentration on the biotransformation

\begin{tabular}{|c|c|c|c|c|c|}
\hline & \multicolumn{5}{|c|}{ DL-Mandelic acid concentration $\left(\mathbf{g} \cdot \mathrm{L}^{-1}\right)$} \\
\hline & 10 & 20 & 30 & 40 & 50 \\
\hline Reaction time (h) & 8 & 18 & 30 & 42 & 54 \\
\hline Benzoylformic acid concentration ( $\left.\mathrm{g} \cdot \mathrm{L}^{-1}\right)$ & 4.8 & 9.8 & 14.3 & 19.1 & 15.6 \\
\hline Biotransformation efficiency $\left(\mathrm{g} \cdot \mathrm{L}^{-1} \cdot \mathrm{h}^{-1}\right)$ & 0.62 & 0.55 & 0.50 & 0.47 & 0.46 \\
\hline Residual L-mandelic acid $\left(\mathrm{g} \cdot \mathrm{L}^{-1}\right)$ & $<0.005$ & & & & 9.6 \\
\hline Residual D-mandelic acid $\left(\mathrm{g} \cdot \mathrm{L}^{-1}\right)$ & 5.0 & 10.1 & 15.1 & 20.1 & 25.2 \\
\hline Enantiomeric excess (\%) & $>99.5$ & & & & 45.0 \\
\hline
\end{tabular}

Values are the mean of 3 separate determinations.

As shown in Figure 5, under optimal conditions, a concentration of $20.1 \mathrm{~g} \cdot \mathrm{L}^{-1}$ D-mandelic acid and $19.3 \mathrm{~g} \cdot \mathrm{L}^{-1}$ benzoylformic acid was obtained from $40 \mathrm{~g} \cdot \mathrm{L}^{-1}$ of DL-mandelic acid after $42 \mathrm{~h}$ in a batch bioconversion. The biotransformation produced high enantiomeric excess (> 99.5\%) of D-mandelic acid (Figure 6) at high concentrations of D-mandelic acid and benzoylformic acid. Kinetic resolution of DL-mandelic acid also could be performed by other biocatalysis processes. However, the processes using lipase or nitrilase resulted in rather low D-mandelic acid concentrations [1-4,29-31]. Enantioselective oxidation of the L-enantiomer from racemic mandelic acid to prepare D-enantiomer is an attractive procedure because it uses inexpensive starting material and has high product yield. Although Pseudomonas sp. [5-7] and Alcaligenes sp. [8-10] have been previously used to produce D-mandelic acid by this route, the simple active conversion system in this study is a promising alternative because $E$. coli is much easier to operate, the D-mandelic acid degrading activity is totally excluded, and resulting in high yields of the 2 building-block

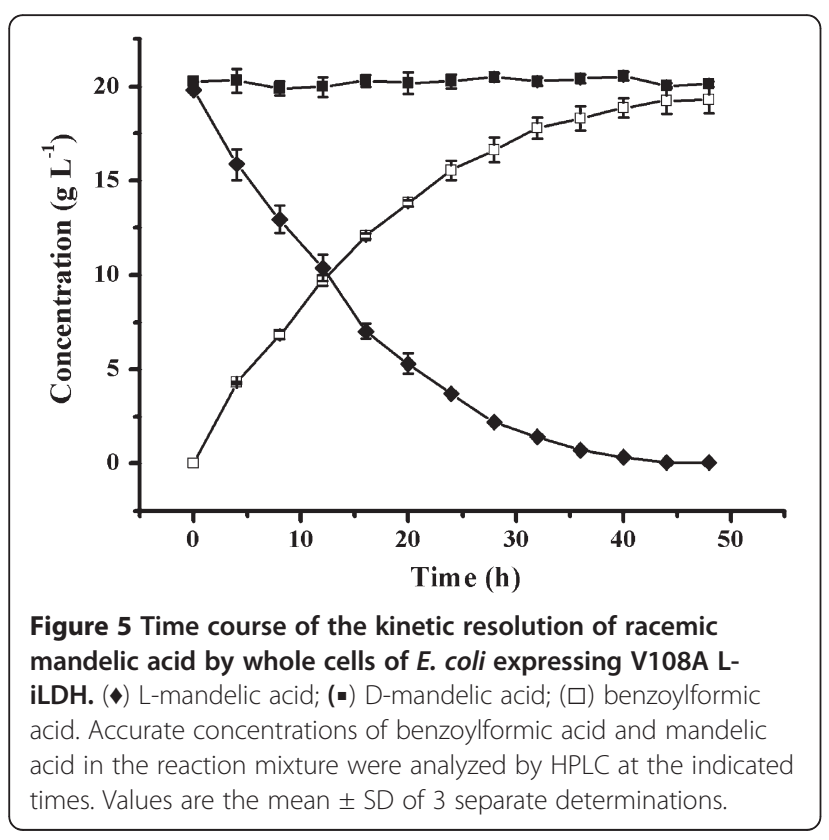

intermediates (D-mandelic acid and benzoylformic acid) by a one-pot biotransformation method.

\section{Conclusions}

In this work, L-iLDH was rationally re-designed on the basis of sequence alignment and the active site structure of a homologous enzyme; a new biocatalyst with high catalytic efficiency toward an unnatural substrate was successfully constructed. A one-pot biotransformation system producing 2 building block intermediates was established using the biocatalyst. Under optimal conditions, a concentration of $20.1 \mathrm{~g} \cdot \mathrm{L}^{-1}$ of D-mandelic acid with high enantiomeric excess (> 99.5\%) and $19.3 \mathrm{~g} \cdot \mathrm{L}^{-1}$ of benzoylformic acid was obtained from $40 \mathrm{~g} \cdot \mathrm{L}^{-1}$ of DLmandelic acid.

\section{Materials and methods \\ Enzymes and chemicals}

Restriction enzymes were purchased from TaKaRa Bio Inc (China). FastPfu DNA polymerase and $\mathrm{T}_{4}$ DNA ligase were purchased from Transgen Biotech (China) and MBI (USA), respectively. D-mandelic acid, L-mandelic acid, racemic mandelic acid, benzoylformic acid, and 2,6-dichloroindophenol (DCIP) were all purchased from Sigma-Aldrich (USA). Isopropyl- $\beta$-D-1-thiogalactopyranoside (IPTG), dithiothreitol (DTT), and phenylmethanesulfonyl fluoride (PMSF) were obtained from Merck (Germany). All other chemicals were of reagent grade.

\section{Site-directed mutagenesis and enzyme expression}

To construct the mutant enzyme with valine-108 changed to alanine (V108A L-iLDH), site-directed mutagenesis was performed using the MutanBEST Kit (TaKaRa). The $l l d D$ gene coding for the wild-type L-iLDH was subcloned into the $\mathrm{pMD}^{\mathrm{TM}} 18-\mathrm{T}$ vector (TaKaRa) to construct the $\mathrm{pMD}^{\mathrm{TM}} 18-\mathrm{T}-l l d D$ vector. The mutation was introduced using the following primers: 5'TTCACCCTTTCCACCGCGTCGGTCT3' and 5'GGGAATCCCTTTCTTGTCTGCCGC3' to amplify the entire sequence of $\mathrm{pMD}^{\mathrm{TM}} 18-\mathrm{T}-l l d D$. The linear $\mathrm{PCR}$ products were then cyclized using the ligase from the MutanBEST Kit. The mutant $l l d D$ gene (confirmed by automated DNA 

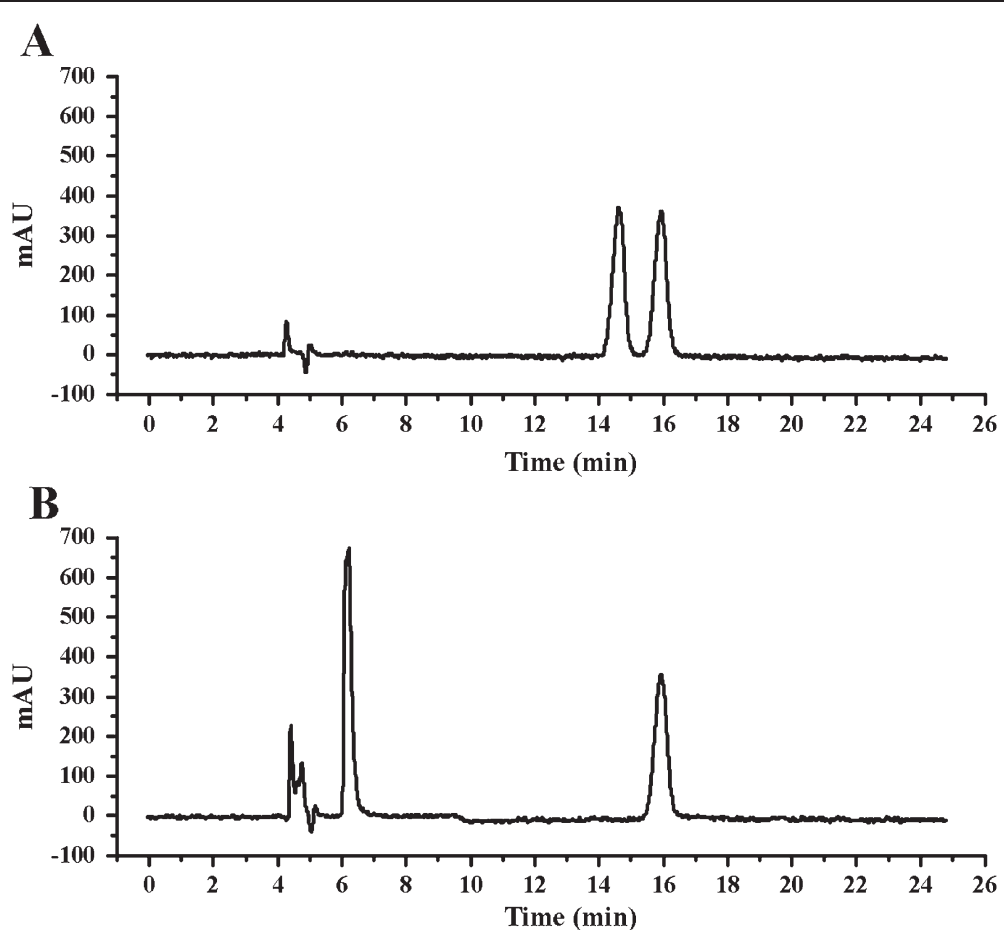

Figure 6 Analysis of optical purity of mandelic acid by HPLC. (A) Sample at the beginning of the biotransformation. (B) Sample at the end of the biotransformation.

sequencing) was subcloned into the HindIII and XhoI restriction sites of the pETDuet-1 expression vector with a T7 promoter. Plasmid purification, DNA manipulation, and transformation were performed by the standard methods described by Sambrook et al. [32]. E. coli DH5 $\alpha$ and C43 (DE3) were used for general cloning and expression procedures, respectively. Lysogenic broth (LB) medium was used for E. coli cultivations. Ampicillin was used at a concentration of $100 \mu \mathrm{g} \cdot \mathrm{mL}^{-1}$.

The expression and purification procedure of wildtype L-iLDH from recombinant $E$. coli has been described previously [12]. The same procedure was used to express and purify the V108A mutant of L-iLDH. The purified enzymes were concentrated by ultrafiltration, desalted with Sephadex G-25, and then stored in $100 \mathrm{mM}$ sodium phosphate buffer $(\mathrm{pH} 8.0$, containing $0.1 \%$ Triton $\mathrm{X}-100$ ) at $-20^{\circ} \mathrm{C}$. The expressed and purified enzyme was confirmed by sodium dodecyl sulfate polyacrylamide gel electrophoresis (SDS-PAGE).

\section{Biochemical assays}

The activities of wild-type and mutant $\mathrm{L}$-iLDH were determined at $30^{\circ} \mathrm{C}$ in $1 \mathrm{~mL}$ of $50 \mathrm{mM}$ Tris- $\mathrm{HCl}, \mathrm{pH}$ 7.5, $0.0625 \mathrm{mM}$ DCIP, and the enzyme. Protein amounts of wild-type enzyme and V108A L-iLDH mutant used to assay the kinetic parameters towards L-lactate were $0.05 \mu \mathrm{g}$ and $0.2 \mu \mathrm{g}$, repectively; $4.0 \mu \mathrm{g}$ and $1.0 \mu \mathrm{g}$ proteins of wild-type and V108A L-iLDH were used to assay the kinetic parameters towards L-mandelate, respectively. The reaction was started by the addition of L-lactate or L-mandelate, and the rates of DCIP reduction were determined by measuring the absorbance change at $600 \mathrm{~nm}$ [33]. To study effects of temperature and $\mathrm{pH}$ on enzyme stability, the enzyme was incubated at different temperature for $0.5 \mathrm{~h}$ or at different $\mathrm{pH}$ for $2 \mathrm{~h}$, and then assayed with $1.25 \mathrm{mM} \mathrm{L}$-lactate as substrate. MTT was used at a concentration of $0.2 \mathrm{mM}$ instead of $0.0625 \mathrm{mM}$ DCIP as electron acceptor in the assay of $\mathrm{pH}$ stability, since the molar extinction coefficient of DCIP changes with different $\mathrm{pH}$. The rate of MTT reduction was determined by measuring changes in absorbance at $578 \mathrm{~nm}$ [34]. One unit of L-iLDH activity was defined as the amount reducing $1.0 \mu \mathrm{mol}$ of electron acceptor per minute under the test conditions. Protein concentration was determined by the Lowry method with BSA as a standard [35].

\section{Biocatalyst preparation}

Recombinant E. coli $\mathrm{C} 43$ (DE3) cells were grown at $37^{\circ} \mathrm{C}$ on a rotary shaker $(180 \mathrm{rpm})$ in LB medium containing ampicillin $\left(100 \mu \mathrm{g} \cdot \mathrm{mL}^{-1}\right)$ to an $\mathrm{OD}_{620}$ of 0.6. Expression of the recombinant gene was induced by adding $1 \mathrm{mM}$ IPTG at the same temperature for $6 \mathrm{~h}$. After induction, the cells were harvested by centrifugation at $6,000 \times g$ for $10 \mathrm{~min}$ at $4{ }^{\circ} \mathrm{C}$ and then washed twice with $0.85 \%$ $\mathrm{NaCl}$. The whole cells resuspended in $\mathrm{ddH}_{2} \mathrm{O}$ were used 
as the biocatalyst for the kinetic resolution of DL-mandelic acid.

\section{Optimization of biotransformation conditions}

To optimize the biotransformation conditions, 20-mL samples of the reaction mixture in a $100-\mathrm{mL}$ flask were used. Ethylenediaminetetraacetic acid (EDTA) was added to a concentration of $20 \mathrm{mM}$ in the reaction system. The biocatalysts were prepared from $12.5 \mathrm{~g}$ (DCW) $\mathrm{L}^{-1}$ of $E$. coli C43 (DE3) expressing the V108A mutant L-iLDH for the optimization of $\mathrm{pH}$ and temperature. The $\mathrm{pH}$ was adjusted from 4.0 to 10.0. The temperatures ranges were from $16^{\circ} \mathrm{C}$ to $58^{\circ} \mathrm{C}$. The activity of whole-cell biocatalyst was judged by the concentration of benzoylformic acid produced. The DL-mandelic acid concentrations were $10.0-50.0 \mathrm{~g} \cdot \mathrm{L}^{-1}$, and the biotransformation was performed at $42^{\circ} \mathrm{C}$ at $\mathrm{pH} 7.0$ for $12-54 \mathrm{~h}$ with $25 \mathrm{~g}$ (DCW) $\mathrm{L}^{-1}$ of biocatalyst.

\section{Analytical methods}

Accurate concentrations of mandelic acid and benzoylformic acid were analyzed by high-performance liquid chromatography (HPLC, Agilent 1100 series, USA) using an Aminex HPX-87H column (Bio-Rad, USA) and the eluent using $10 \mathrm{mM} \mathrm{H}_{2} \mathrm{SO}_{4}$ solution at a flow rate of $0.4 \mathrm{~mL} \cdot \mathrm{min}^{-1}$. Samples from reaction systems during biocatalysis were centrifuged at 140,000 $\times g$ for $5 \mathrm{~min}$ to remove cells, and the supernatant was filtered by $0.22 \mu \mathrm{m}$ pore size membrane filter for HPLC analysis.

Stereoselective assays of D-mandelic acid and L-mandelic acid were performed by HPLC analysis using a chiral column (DAICEL CHIRALCEL OJ-RH, Japan) and a tunable UV detector at $205 \mathrm{~nm}$. The mobile phase consisted of $90 \% \mathrm{H}_{2} \mathrm{O}$ (with $0.1 \%$ acetic acid added) and $10 \%$ acetonitrile $(\mathrm{v} / \mathrm{v})$ pumped at $0.4 \mathrm{~mL} \cdot \mathrm{min}^{-1}\left(15^{\circ} \mathrm{C}\right)$. Samples were prepared by the same procedure as using Aminex HPX-87H column. The optical purity of D-mandelate was expressed as enantiomeric excess (ee value), which was defined as the ratio of $\frac{(D-\text { mandelic acid })-(L-\text { mandelic acid })}{(D-\text { mandelic acid })+(L-\text { mandelic acid })} \times 100 \%$.

\section{Additional files}

\section{Additional file 1: Figure S1. The active site structure of}

flavocytochrome $\boldsymbol{b}_{2}$. The figure is generated according to the molecular structure of flavocytochrome $b_{2}$ at $2.4 \AA$ resolution (PDB code 1FCB) [23] with PyMOL (The PyMOL Molecular Graphics System, Version 0.99rc6, Schrödinger, LLC). The pyruvate ligand, as oxidation product of L-lactate, is shown in orange. The residues interact directly to the substrate are shown in blue. The residue labels in parentheses are the corresponding residues of $\mathrm{L}-\mathrm{iLDH}$, which are identified by sequence alignment.

Additional file 2: Figure S2. Inhibition of V108A L-iLDH by D-mandelate. Purified V108A L-iLDH $(1 \mu \mathrm{g})$ was incubated in the reaction mixture contained $0.0625 \mathrm{mM} \mathrm{DCIP}$ and $50 \mathrm{mM}$ Tris- $\mathrm{HCl}(\mathrm{pH} 7.5)$ at $30^{\circ} \mathrm{C}$. The reaction was started with different L-mandelate concentrations at variable D-mandelate concentrations. •, no
D-mandelate; $\bullet 6.25$ mM D-mandelate; $\bullet, 12.5$ mM D-mandelate; $\boldsymbol{~}$, $25 \mathrm{mM}$ D-mandelate; $\bullet, 37.5 \mathrm{mM}$ D-mandelate. The patterns of double-reciprocal plots indicate a competitive inhibition. The $K_{\mathrm{i}}$ value was estimated to be $5.5 \pm 0.5 \mathrm{mM}$.

Additional file 3: Figure S3. The stability of wild-type and V108A L-iLDH as function of temperature and $\mathrm{pH}$. (A) The effect of

temperature on the enzyme stability. The enzyme was incubated at different temperature ranging from $16^{\circ} \mathrm{C}$ to $58^{\circ} \mathrm{C}$ for $0.5 \mathrm{~h}$ and then assayed. The enzyme activity without treatment (store at $4^{\circ} \mathrm{C}$ ) was defined as 100\%. - wild-type L-iLDH; •, V108A L-iLDH. (B) The effect of pH on the enzyme stability. The enzyme was incubated at different $\mathrm{pH}$ ranging from 3.0 to 11.0 for $2 \mathrm{~h}$ and then assayed. The buffers were: $0.2 \mathrm{M} \mathrm{Na}_{2} \mathrm{HPO}_{4}-0.1 \mathrm{M}$ citric acid buffer for $\mathrm{pH}$ 3.0-8.0; $50 \mathrm{mM}$

Glycine-NaOH buffer for pH 8.0-12.0. The enzyme activities of wild-type and V108A L-iLDH without pH treatment (stored in $100 \mathrm{mM}$ sodium phosphate buffer, pH 8.0) was defined as $100 \%$ severally. MTT was used at a concentration of $0.2 \mathrm{mM}$ instead of $0.0625 \mathrm{mM}$ DCIP as electron acceptor in the assay of $\mathrm{pH}$ stability, for the molar extinction coefficient of DCIP changes with different pH. $\cdot$, wild-type L-iLDH;, V108A L-iLDH. Values are the mean \pm SD of 3 separate determinations.

Additional file 4: Figure S4. HPLC analysis of the chiral products of the reaction catalyzed by V108A L-iLDH. (A) Authentic D-mandelic acid; (B) authentic L-mandelic acid; (C) reaction mixture at the beginning of the reaction (solid line), after $4 \mathrm{~h}$ (short dot line), and after $10 \mathrm{~h}$ (dash dot line). The biotransformation was carried out using $12.5 \mathrm{~g}$ (DCW) $\mathrm{L}^{-1}$ of $E$. coli expressing V108A L-iLDH as the biocatalyst and $10 \mathrm{~g}^{-\mathrm{L}^{-1}}$ DL-mandelic acid as the substrate. The analytical methods are described in the "Materials and methods".

Additional file 5: Figure S5. The inhibition effect of D-mandelic acid on the whole-cell biocatalyst activity. Different concentrations of D-mandelic acid (from $0 \mathrm{~g} \cdot \mathrm{L}^{-1}$ to $30 \mathrm{~g} \cdot \mathrm{L}^{-1}$ ) were added to reaction systems containing $10 \mathrm{~g} \cdot \mathrm{L}^{-1} \mathrm{~L}$-mandelic acid. The activity of whole-cell biocatalyst was judged by the concentration of benzoylformic acid produced within $4 \mathrm{~h}$ of reaction. Values are the mean \pm SD of 3 separate determinations.

Additional file 6: Figure S6. HPLC analysis of the products from the reaction catalyzed by V108A L-iLDH. (A) Authentic mandelic acid; (B) authentic benzoylformic acid; (C) reaction mixture after $8 \mathrm{~h}$ of reaction without adding EDTA; (D) reaction mixture after $8 \mathrm{~h}$ of reaction with $20 \mathrm{mM}$ EDTA added. The biotransformation was carried out using $25 \mathrm{~g}$ (DCW) $L^{-1}$ of E. coli expressing V108A L-iLDH as the biocatalyst and $10 \mathrm{~g}^{-1} \mathrm{~L}^{-1} \mathrm{DL}$-mandelic acid as the substrate. The analytical methods are described in the "Materials and methods."

\section{Competing interests}

The authors declare that they have no competing interests.

\section{Authors' contributions}

PX and CM designed experiments. TJ, CG and PD performed experiments. CM and JK contributed reagents and materials. TJ and CG analyzed data. TJ, PX and CM wrote the manuscript. All authors have read and approved the final manuscript.

\section{Acknowledgments}

The work was supported by National Natural Science Foundation of China (31170052) and Chinese National Program for High Technology Research and Development (2011AA02A207).

The authors thank Professor Jan-Willem de Gier for providing E. coli C43 (DE3) for protein expression.

\section{Author details}

${ }^{1}$ State Key Laboratory of Microbial Technology, Shandong University, Jinan 250100, China. ${ }^{2}$ State Key Laboratory of Microbial Metabolism and Schoolof Life Sciences and Biotechnology, Shanghai Jiao Tong University, Shanghai 200240, China. 


\section{References}

1. Yamamoto K, Oishi K, Fujimatsu I, Komatsu K: Production of R-(-)-mandelic acid from mandelonitrile by Alcaligenes faecalis ATCC 8750. Appl Environ Microbiol 1991, 57:3028-3032.

2. Kaul P, Banerjee A, Mayilraj S, Banerjee UC: Screening for enantioselective nitrilases: kinetic resolution of racemic mandelonitrile to (R)-(-)-mandelic acid by new bacterial isolates. Tetrahedron-Asymmetry 2004, 15:207-211.

3. He Y, Xu J, Xu Y, Ouyang L, Pan J: Biocatalytic synthesis of (R)(-)-mandelic acid from racemic mandelonitrile by a newly isolated nitrilase-producer Alcaligenes sp. ECU0401. Chin Chem Lett 2007, 18:677-680

4. Choi WJ, Lee KY, Kang SH, Lee SB: Biocatalytic enantioconvergent separation of racemic mandelic acid. Sep Purif Technol 2007, 53:178-182.

5. Kim BY, Hwang KC, Song HS, Chung N, Bang WG: Optical resolution of RS-(+/-)-mandelic acid by Pseudomonas sp. Biotechnol Lett 2000, 22:1871-1875.

6. Takahashi E, Nakamichi K, Furui M, Mori T: R-(-)-mandelic acid production from racemic mandelic acids by Pseudomonas polycolor with asymmetric degrading activity. J Ferment Bioeng 1995, 79:439-442

7. Takahashi E, Nakamichi K, Furui M: R-(-)-mandelic acid production from racemic mandelic acids using Pseudomonas polycolor IFO 3918 and Micrococcus freudenreichii FERM-P 13221. J Ferment Bioeng 1995, 80:247250.

8. Miyamoto $\mathrm{K}$, Ohta $\mathrm{H}$ : Enantioselective oxidation of mandelic acid using a phenylmalonate metabolizing pathway of a soil bacterium Alcaligenes bronchisepticus KU 1201. Biotechnol Lett 1992, 14:363-366.

9. He Y, Xu J, Pan J, Ouyang L, Xu Y: Preparation of (R)-(-)-mandelic acid and its derivatives from racemates by enantioselective degradation with a newly isolated bacterial strain Alcaligenes sp. ECU0401. Bioprocess Biosyst Eng 2008, 31:445-451.

10. Tsuchiya S, Miyamoto $\mathrm{K}$, Ohta $\mathrm{H}$ : Highly efficient conversion of ( \pm -mandelic acid to its (R)-(-)-enantiomer by combination of enzyme-mediated oxidation and reduction. Biotechnol Lett 1992 14:1137-1142.

11. Gao C, Ma C, Xu P: Biotechnological routes based on lactic acid production from biomass. Biotechnol Adv 2011, 29:930-939.

12. Gao C, Jiang T, Dou P, Ma C, Li L, Kong J, Xu P: NAD-Independent L-lactate dehydrogenase is required for L-lactate utilization in Pseudomonas stutzeri SDM. PLoS One 2012, 7:e36519.

13. Gao C, Qiu J, Li J, Ma C, Tang H, Xu P: Enantioselective oxidation of racemic lactic acid to D-lactic acid and pyruvic acid by Pseudomonas stutzeri SDM. Bioresour Technol 2009, 100:1878-1880.

14. Gao C, Zhang W, Ma C, Liu P, Xu P: Kinetic resolution of 2hydroxybutanoate racemic mixtures by NAD-independent L-lactate dehydrogenase. Bioresour Technol 2011, 102:4595-4599.

15. Seah SY, Britton KL, Baker PJ, Rice DW, Asano Y, Engel PC: Alteration in relative activities of phenylalanine dehydrogenase towards different substrates by site-directed mutagenesis. FEBS Lett 1995, 370:93-96.

16. Seah SY, Britton KL, Rice DW, Asano Y, Engel PC: Single amino acid substitution in bacillus sphaericus phenylalanine dehydrogenase dramatically increases its discrimination between phenylalanine and tyrosine substrates. Biochemistry 2002, 41:11390-11397.

17. Paradisi F, Collins S, Maguire AR, Engel PC: Phenylalanine dehydrogenase mutants: efficient biocatalysts for synthesis of non-natural phenylalanine derivatives. J Biotechnol 2007, 128:408-411.

18. Paradisi F, Conway PA, Maguire AR, Engel PC: Engineered dehydrogenase biocatalysts for non-natural amino acids: efficient isolation of the D-enantiomer from racemic mixtures. Org Biomol Chem 2008, 6:3611-3615.

19. Chen S, Engel PC: Efficient screening for new amino acid dehydrogenase activity: directed evolution of Bacillus sphaericus phenylalanine dehydrogenase towards activity with an unsaturated non-natural amino acid. J Biotechnol 2009, 142:127-134.

20. Wilks HM, Halsall DJ, Atkinson T, Chia WN, Clarke AR, Holbrook JJ: Designs for a broad substrate specificity keto acid dehydrogenase. Biochemistry 1990, 29:8587-8591.

21. Sacchi S, Lorenzi S, Molla G, Pilone MS, Rossetti C, Pollegioni L: Engineering the substrate specificity of D-amino-acid oxidase. J Biol Chem 2002, 277:27510-27516.
22. Black MT, White SA, Reid GA, Chapman SK: High-level expression of fully active yeast flavocytochrome $b_{2}$ in Escherichia coli. Biochem J 1989, 258:255-259.

23. Xia ZX, Mathews FS: Molecular structure of flavocytochrome $b_{2}$ at $2.4 \AA$ resolution. J Mol Biol 1990, 212:837-863.

24. Daff S, Manson FD, Reid GA, Chapman SK: Strategic manipulation of the substrate specificity of Saccharomyces cerevisiae flavocytochrome $b_{2}$. Biochem J 1994, 301:829-834.

25. Sinclair R, Reid GA, Chapman SK: Re-design of Saccharomyces cerevisiae flavocytochrome $b_{2}$ : introduction of L-mandelate dehydrogenase activity. Biochem J 1998, 333:117-120.

26. Thompson JD, Gibson TJ, Plewniak F, Jeanmougin F, Higgins DG: The CLUSTAL_X windows interface: flexible strategies for multiple sequence alignment aided by quality analysis tools. Nucleic Acids Res 1997, 25:4876-4882.

27. Gouet P, Courcelle E, Stuart DI, Metoz F: ESPript: analysis of multiple sequence alignments in PostScript. Bioinformatics 1999, 15:305-308.

28. Ma C, Xu P, Dou Y, Qu Y: Highly efficient conversion of lactate to pyruvate using whole cells of Acinetobacter sp. Biotechnol Prog 2003, 19:1672-1676

29. Xue $Y, X u$ S, Liu Z, Zheng $Y$, Shen $Y$ : Enantioselective biocatalytic hydrolysis of $(r, s)$-mandelonitrile for production of $(r)-(-)$-mandelic acid by a newly isolated mutant strain. $J$ Ind Microbiol Biotechnol 2011, 38:337-345.

30. Rey P, Rossi JC, Taillades J, Gros G, Nore O: Hydrolysis of nitriles using an immobilized nitrilase: applications to the synthesis of methionine hydroxy analogue derivatives. J Agric Food Chem 2004, 52:8155-8162.

31. Yadav GD, Sivakumar P: Enzyme-catalysed optical resolution of mandelic acid via $\mathrm{RS}(-/+)$-methyl mandelate in non-aqueous media. Biochem Eng J 2004, 19:101-107.

32. Sambrook J, Fritsch EF, Maniatis T: Molecular Cloning: A Laboratory Manual. 2nd edition. Cold Spring Harbor, NY: Cold Spring Harbor Laboratory Press: 1989

33. Janssen AJ, Trijbels FJ, Sengers RC, Smeitink JA, van den Heuvel LP, Wintjes LT, Stoltenborg-Hogenkamp BJ, Rodenburg RJ: Spectrophotometric assay for complex I of the respiratory chain in tissue samples and cultured fibroblasts. Clin Chem 2007 , 53:729-734.

34. Nagel M, Andreesen JR: Purification and characterization of the molybdoenzymes nicotinate dehydrogenase and 6-hydroxynicotinate dehydrogenase from Bacillus niacini. Arch Microbiol 1990, 154:605-613.

35. Markwell MA, Haas SM, Bieber LL, Tolbert NE: A modification of the Lowry procedure to simplify protein determination in membrane and lipoprotein samples. Anal Biochem 1978, 87:206-210.

doi:10.1186/1475-2859-11-151

Cite this article as: Jiang et al:: Rationally re-designed mutation of NADindependent L-lactate dehydrogenase: high optical resolution of racemic mandelic acid by the engineered Escherichia coli. Microbial Cell Factories 2012 11:151.

\section{Submit your next manuscript to BioMed Central and take full advantage of:}

- Convenient online submission

- Thorough peer review

- No space constraints or color figure charges

- Immediate publication on acceptance

- Inclusion in PubMed, CAS, Scopus and Google Scholar

- Research which is freely available for redistribution 